\title{
MOBILIZAÇÃO, RECONHECIMENTO IDENTITÁRIO E O ACESSO A POLÍTICAS PÚBLICAS PELA COMUNIDADE QUILOMBOLA ALAGADIÇO NO MUNICÍPIO DE JUAZEIRO-BA ${ }^{1}$
}

\author{
Danilo Moreira dos Santos ${ }^{2}$ \\ iD https://orcid.org/0000-0002-8644-1805 \\ Nilton de Almeida Araújo ${ }^{3}$ \\ iD https://orcid.org/0000-0002-7173-5245
}

\begin{abstract}
RESUMO
A necessidade de atenção à especificidade quilombola tem se justificado pela noção de um segmento historicamente relegado a um contexto de vulnerabilidade, impondo-se a premência de ações que compreendam o reconhecimento da identidade e territorialidade, e o acesso a serviços e recursos no âmbito de políticas públicas fundamentais. Este artigo busca analisar o acesso a políticas públicas na Comunidade Quilombola Alagadiço, em Juazeiro-Bahia, situando o contexto de sua mobilização em torno do direito a tais prerrogativas, concernente ao aspecto da afirmação identitária. A pesquisa de campo, realizada em 2017, compreende a aplicação de questionário a pessoas de 13 residências e gravação de entrevista semiestruturada com dois moradores, além de observações e entrevistas informais realizadas em complemento a essas estratégias metodológicas. Demonstra-se, no contexto de afirmação da identidade, como Alagadiço se insere num complexo quadro de relações que envolve muitas comunidades negras rurais, verificando-se, em paralelo, um limitado acesso a recursos e serviços e um atendimento generalista que pouco compreende a especificidade étnica, sendo ainda recente a conquista do reconhecimento oficial, ocorrida em 2016. Aponta-se, nesse sentido, uma incipiente atenção do poder público para com a comunidade, realidade que começa a mudar com esse ingresso na política de reconhecimento oficial e a busca pela regularização do território, que, no entanto, demanda um contínuo engajamento dos próprios sujeitos em meio a esse processo de mobilização.
\end{abstract}

Palavras-chave: Comunidade Quilombola, Políticas Públicas, Políticas de Reconhecimento Quilombola, Alagadiço, Juazeiro-BA.

\section{MOBILIZATION, IDENTITY RECOGNITION AND ACCESS TO PUBLIC POLICIES BY THE COMMUNITY QUILOMBOLA ALAGADIÇO IN THE MUNICIPALY OF THE JUAZEIRO-BA}

\begin{abstract}
The need for attention to quilombola specificity has been justified by the notion of a segment historically relegated to a context of vulnerability, imposing the urgency of actions that include the recognition of identity and territoriality and access to services and resources within the scope of fundamental public policies. This article analyzes the access to public policies in the Alagadiço Quilombola Community, in Juazeiro-Bahia, situating the context of its mobilization around the right to such prerogatives, concerning the aspect of the identity affirmation. Field research, held in 2017, includes the application of questionnaire to people from 13 residences and gravation of semi-

\footnotetext{
${ }^{1}$ Uma versão preliminar foi discutida no Grupo de Trabalho "Autossustentabilidade de grupos étnicos afrobrasileiros", durante o primeiro Congresso Internacional Interdisciplinar em Extensão Rural e Desenvolvimento (CIIERD), realizado na Universidade Federal do Vale do São Francisco (Univasf), campus Juazeiro-BA, de 28 a 30 de outubro de 2017.

${ }^{2}$ Bacharel em Ciências Sociais. Mestre pelo Programa de Pós-Graduação em Extensão Rural (PPGExR) da Univasf. Email: danilo-2010moreira@hotmail.com.

${ }^{3}$ Doutor em História Social. Professor vinculado ao Programa de Pós-Graduação em Extensão Rural (PPGExR) da Univasf. E-mail: nilton.almeida@univasf.edu.br.
} 
structured interview with two residents, as well as observations and informal interviews carried in a complementary way to this methodological strategy. It is demonstrated, in the context of identity affirmation, how Alagadiço is inserted in a complex frame of relations that involves many rural black communities, being verified, in parallel, a limited access to resources and services and a generalist attention that little meets the specificity ethnic, being still recent the conquist of the oficial recognition, occurred in 2016. It is point out, in this sense, an incipient attention of the public power towards the community, a reality that begins to change with this entrance in the politics of official recognition and the search for the regularization of the territory, which, nevertheless, demands a continuous engagement of the subjects themselves in the midst of this process of mobilization.

Key words: Quilombola Community, Public Policies, Politics of Quilombo Recognition, Alagadiço, Juazeiro-BA.

\section{MOVILIZACIÓN, RECONOCIMIENTO DE IDENTIDAD Y ACCESO A LAS POLÍTICAS PÚBLICAS POR LA COMUNIDAD QUILOMBOLA ALAGADIÇO EN EL MUNICIPIO DE JUAZEIRO-BA}

\section{RESUMEN}

La necesidad de prestar atención a la especificidad de los quilombolas está justificada por la noción de un segmento históricamente relegado a un contexto de vulnerabilidad, que impone la urgencia de acciones que incluyen el reconocimiento de la identidad y la territorialidad y el acceso a servicios y recursos dentro del alcance de las políticas públicas fundamentales. Este artículo busca analizar el acceso a las políticas públicas en la Comunidad Quilombola Alagadiço, en Juazeiro-Bahía, situando el contexto de su movilización en torno al derecho a tales prerrogativas, en relación con el aspecto de la afirmación de identidad. La investigación de campo, realizada en 2017, comprende la aplicación de un cuestionario a personas de 13 residencias y el registro de una entrevista semiestructurada con dos residentes, además de observaciones y entrevistas informales realizadas en adición de estas estrategias metodológicas. Se demuestra, en el contexto de la afirmación de identidad, cómo se inserta Alagadiço en un complejo marco de relaciones que involucra a muchas comunidades negras rurales, en paralelo, con acceso limitado a recursos y servicios y asistencia general que poco atende la especificidad étnica. Sin embargo, aún es reciente el reconocimiento oficial, que ocurrió en 2016. En este sentido, existe una atención incipiente de las autoridades hacia la comunidad, una realidad que comienza a cambiar con esta entrada en la política de reconocimiento oficial y la búsqueda de regularización del territorio, que, sin embargo, exige un compromiso continuo de los propios sujetos en medio de este proceso de movilización.

Palabras-clave: Comunidad Quilombola, Políticas Públicas, Políticas de Reconocimiento de Quilombola, Alagadiço, Juazeiro-BA.

\section{INTRODUÇÃO}

Geralmente remetidos a um processo de resistência ao sistema de dominação escravista, os povos quilombolas caracterizam-se como agrupamentos étnicos, cuja forma de estabelecimento na sociedade brasileira não possibilitou um lugar tão favorável, tendo sido historicamente relegados a um estado de vulnerabilidade. Em meio a esse contexto, tem se verificado a necessidade de atenção às suas especificidades, com ações que compreendam medidas de cunho reparativo, reconhecimento, valorização e proteção de sua cultura, identidade e territorialidade, e o acesso a recursos e serviços implementados mediante a introdução de políticas públicas específicas. 
Nesse cenário de atenção a grupos específicos, vem se inserindo uma das 14 Comunidades Negras Rurais Quilombolas (CNRQs) pertencentes ao município de Juazeiro-BA ${ }^{4}$, a comunidade Alagadiço. Após um longo processo, essa comunidade se tornou, em maio de 2016, a primeira no município a conquistar a oficialização do reconhecimento junto à Fundação Cultural Palmares (FCP), sendo publicada em 20 de maio de 2016, no Diário Oficial da União, a Portaria de $n^{\circ} 103$ (Brasil, 2016), que dá publicidade ao fato. Isso representa um passo à frente na busca pela garantia do território, na luta pelo reconhecimento identitário e em direção à possibilidade de um maior acesso a programas e políticas públicas de atenção a povos e comunidades quilombolas.

Neste trabalho, discute-se o acesso da população da CNRQ Alagadiço a políticas públicas e serviços em diversas áreas, abordando o contexto de sua mobilização em torno do direito a essas ações, a partir de sua inserção como público específico. O interesse pelo desenvolvimento da pesquisa nessa comunidade se justifica exatamente pelo fato de ela ter conseguido, através de mobilização, a certificação pela Fundação Cultural Palmares, um quesito que a coloca em posição mais específica na seara de luta pela melhoria de suas condições de vida, o que, em tese, deve se dar principalmente pelo acesso a serviços essenciais abarcados por políticas públicas, muitas das quais conquistadas somente nas últimas décadas. Nesse grupo estão, por exemplo, aquelas compreendidas no âmbito do Programa Brasil Quilombola (PBQ), introduzido em 12 de março de 2004 (Brasil, 2013, p. 10), e ações com abordagem transversal, como a Política Nacional de Assistência Técnica e Extensão Rural (PNATER), institucionalizada, após várias reformulações ${ }^{5}$, no ano de 2010, através da Lei ${ }^{\circ} 12.188$, a qual dentre os beneficiários também enumera os quilombolas como público específico a ser atendido, juntamente com os povos indígenas e demais povos e comunidades tradicionais e assentados da reforma agrária (Brasil, 2010a).

Aborda-se a noção de política pública em um sentido amplo, considerando-se o fato de que "Não existe uma única, nem melhor, definição sobre o que seja política pública.” (Sousa, 2006, p. 24), embora grande parte das definições busque “[...] a ideia de que a policy-making é um processo

\footnotetext{
${ }^{4}$ Juazeiro é um município com 197.965 habitantes, dos quais 73\% são negros (pretos e pardos) (BRASIL, 2010). Dados divulgados pelo projeto Geografia dos Assentamentos na Área Rural (GeografAR), em 2011, apontaram 14 CNRQs identificadas no município: Alagadiço, Aldeia, Angico, Barrinha do Cambão, Barrinha da Conceição, Capim de Raiz, Curral Novo, Deus Dará, Junco, Passagem, Pau Preto, Quebra Facão, Quipá e Rodeadouro (INCRA; CDA; CPP; CPT, 2010 apud GeografAR, 2011, p. 12-13). No período inicial de realização dessa pesquisa, dessas 14 CNRQs, somente Alagadiço era certificada como comunidade remanescente quilombola. Posteriormente, em 05 de julho de 2018 , a comunidade Rodeadouro também foi certificada. E, no dia 23 de novembro de 2018, ocorreu a terceira certificação, sendo a vez da comunidade Barrinha da Conceição. Algumas das demais comunidades se encontram, atualmente, em processo de etnogênese.

${ }^{5}$ Há referências a formulações anteriores dessa medida (a PNATER-2010) enquanto política nacional, como aquela introduzida no ano de 2001, através do Conselho Nacional de Desenvolvimento Rural Sustentável (CNDRS/atual Condraf), havendo sua reapresentação com modificações no ano de 2003. Assim, “[...] ao longo de 2003 [...] foi construída pelo MDA uma nova Política Nacional de Assistência Técnica e Extensão Rural (PNATER), de forma mais democrática e participativa que a versão formulada dois anos antes pelo CNDRS [...]." (Peixoto, 2008, p. 37). Após a versão proposta em 2003, a medida foi novamente reapresentada, sofrendo novas alterações e sendo finalmente institucionalizada no ano de 2010, através da referida Lei $n^{\circ} 12.188$, atual Lei de ATER.
} 
técnico-político que visa definir e compatibilizar objetivos e meios entre atores sociais sujeitos à restrições.” (Howlett; Ramesh; Perl, 2013 [2009], p. 6), e, muito embora “A definição mais conhecida continua sendo a de Laswell, ou seja, decisões e análises sobre política pública implicam responder às seguintes questões: quem ganha o quê, por quê e que diferença faz.” (Sousa, 2006, p. 24), ambas orientações que são aplicáveis a este trabalho. Mas, por se tratar aqui de mecanismos em que deve haver o direcionamento a um público específico, considera-se a oposição entre políticas públicas diferenciadas e políticas públicas universais.

Segue-se uma metodologia qualitativa. Na pesquisa de campo, realizou-se gravação de entrevista semiestruturada com dois moradores mais antigos e integrantes da associação quilombola, os quais compartilham o conhecimento da história local: um senhor de 65 anos e uma senhora de 68. Também se procedeu à aplicação de questionário (com 21 perguntas, entre abertas e fechadas) em 13 unidades familiares, cujos respondentes estavam disponíveis e concordaram em participar, quando das três visitas realizadas à comunidade, sendo dez respondentes mulheres, um respondente homem e, nos outros dois casos, houve alternância entre marido e mulher na concessão de respostas ao questionário $^{6}$. Ambas as ferramentas contemplaram perguntas sobre o acesso a serviços e programas, formas de subsistência e também sobre autopercepção identitária e herança cultural, entre outras. Em complemento, também foram realizadas observações e entrevistas informais, visando uma maior compreensão de aspectos pouco aprofundados. Essa pesquisa foi iniciada no ano de 2017, tendo se executado a coleta de dados in loco no período de julho a agosto do referido ano.

\section{IDENTIDADE QUILOMBOLA: ENTRE CONCEITOS E RESSIGNIFICAÇÕES}

Atualmente os povos e comunidades quilombolas são definidos como grupos étnicos de identidade autodefinida, com predominância de pessoas negras, e cujo marco identitário encontra sustentação em elementos de sua própria cultura, principalmente enquanto sinais que, em sentido socioantropológico, possam ser compreendidos como socialmente significativos a partir da ótica dos próprios sujeitos. Sobre esses elementos, tem-se como exemplo: o parentesco e a ancestralidade, relações específicas com a terra e com o território, e a singularidade das suas tradições culturais. Encontram-se estas formações sociais tanto no meio rural, quanto no urbano.

A identificação da presença quilombola em solo brasileiro compreende todo um contexto de ressignificações. Sabe-se que hoje a definição de quilombo tem se estabelecido a partir da compreensão de um sentido sociocultural, contudo, até chegar a esse ponto,

\footnotetext{
${ }^{6}$ Por necessidade, em alguns casos o questionário foi diretamente preenchido pelo próprio pesquisador, anotando-se fielmente a resposta do entrevistado e marcando-se os campos relacionados, nas perguntas fechadas.
} 
O que prevaleceu, no Brasil, ao longo da história colonial, imperial e parte da republicana, foi um conceito cristalizado do que seja quilombo, construído a partir da ótica do poder instituído, negando todo um modo de vida e culturas dos sujeitos dessas comunidades, suas formas de lutas e resistências contra a exploração destes mesmos senhores que, assim, conceituavam os quilombos. (Sousa, 2011, p. 37).

Nos primeiros momentos de sua classificação, os quilombos estiveram marcados por processos de negação e cerceamento da autonomia e liberdade de sujeitos e grupos constituídos. Assim, nesse contexto de repressão "Alguns quilombos tiveram longa duração, como o de Palmares, no nordeste do país [que perdurou graças à grande capacidade de resistência apresentada]. Mas a maioria dos quilombos durava pouco porque era logo atacada por forças do governo ou de particulares." (Carvalho, 2002, p. 48).

Hoje não cabe mais uma conceituação que compreenda somente as bases do período colonial, em que o sentido de quilombo estava associado tão somente à repressão à fuga de pessoas do regime escravista e sua coabitação noutro espaço, mais precisamente "toda habitação de negros fugidos que passem de cinco" (Almeida, 2002, p. 47), definição apresentada ao rei de Portugal, em 1740, pelo Conselho Ultramarino Português, segundo esse autor.

Tendo permanecido por muito tempo vinculado a esse contexto de repressão, a referência ao elemento quilombola só assumiu uma nova orientação depois de passados 100 anos da Abolição, conforme Sousa (2011, p. 37), segundo o qual foi somente no âmbito da Constituição Federal de 1988 que o termo quilombo viria a assumir um caráter legal. Isso se verifica, por exemplo, no artigo 216: "Ficam tombados todos os documentos e os sítios detentores de reminiscências históricas dos antigos quilombos.” (Brasil, 1988); e também no Art. 68 dos Atos das Disposições Constitucionais Transitórias (ADCT): “Aos remanescentes das comunidades dos quilombos que estejam ocupando suas terras é reconhecida a propriedade definitiva, devendo o Estado emitir-lhes os respectivos títulos." (Brasil, 1988). Contudo, a terminologia "remanescentes das comunidades dos Quilombos" é criticada por aquele autor, entre muitos outros, por entendê-la como uma classificação que remete à ideia de comunidade quilombola como uma "sobra" e também como algo ultrapassado, ficando o termo ainda vinculado à sua antiga noção.

Em complemento aos pressupostos do Art. 68 ADCT, após uma série de reformulações de argumentos legais, o Decreto $\mathrm{n}^{\circ} 4.887 / 2003$ veio tornar mais explícito o conceito de "Remanescentes das Comunidades dos Quilombos", até então pouco definido, definindo-os como “[...] grupos étnicoraciais, segundo critérios de auto-atribuição, com trajetória histórica própria, dotados de relações territoriais específicas, com presunção de ancestralidade negra relacionada com a resistência à opressão histórica sofrida.” (Brasil, 2003).

Além dessa definição jurídica introduzida pelo aparato constitucional para orientação das políticas de reconhecimento e reparação pelo Estado, e que após várias décadas veio a ser explicada 
pelo Decreto $\mathrm{n}^{\circ} 4.887 / 2003$, também é adotado o conceito anteriormente cunhado de "comunidades negras rurais". Compreendido como não redutor do fenômeno quilombola, este teria se originado no Movimento Negro, assumindo um significado político e referindo-se a diferentes situações sociais que envolvem a categoria étnica em questão (Almeida, 1998).

Em meio a um contexto em que vários atores e interesses estão envolvidos, permanece um esforço atual na busca pela firmação da (re)conceituação que favoreça o significado sociocultural da identidade quilombola, de forma que toda comunidade negra com potencial identitário, tanto rural quanto urbana, mesmo aquelas que foram se formando no pós-abolição, possam se perceber enquanto beneficiárias do direito de oficialização do autorreconhecimento e outras prerrogativas legais. Nesse sentido, como defendem Santos e Doula (2008), para além do componente histórico, que não deve ser esquecido, o pertencimento quilombola é uma orientação que "[...] se concebe a partir de um projeto de autodefinição, de uma articulação cultural de comunidades negras que, de alguma forma, se aglomeraram e preservam relações identitárias com a cultura afro-brasileira." (Santos; Doula, 2008, p. 72). Ainda que possa haver resistência de alguns setores avessos, este é um consenso que tem se buscado estabelecer entre movimentos sociais, segmentos acadêmicos e policymakers envolvidos na questão das políticas de reconhecimento quilombola, entre outras esferas capazes de influenciar nos processos de tomada de decisão.

\section{A COMUNIDADE QUILOMBOLA ALAGADIÇO: ASPECTOS DE SUA TRAJETÓRIA E OS EFEITOS INAUGURAIS DO RECONHECIMENTO INDENTITÁRIO}

A comunidade Alagadiço (Fig. 1) está localizada a 18 quilômetros do centro da cidade de Juazeiro, na região do Semiárido Norte Baiano, distante cerca de meio quilômetro das margens do Rio São Francisco e em posição geográfica situada entre a localidade de Lagoa do Salitre e o povoado do Rodeadouro, próximo do qual está localizada a Ilha do Rodeadouro, que representa um importante ponto turístico bastante frequentado na região. Além da cidade do Juazeiro, é com aqueles dois povoados que a comunidade mais exerce relações de proximidade, culminando no acesso a serviços básicos, como, por exemplo, a realização de consultas médicas e também o acesso de crianças e jovens à educação escolar naquele primeiro povoado. 
Figura 1: Principal núcleo residencial da comunidade Alagadiço, próximo ao rio São Francisco

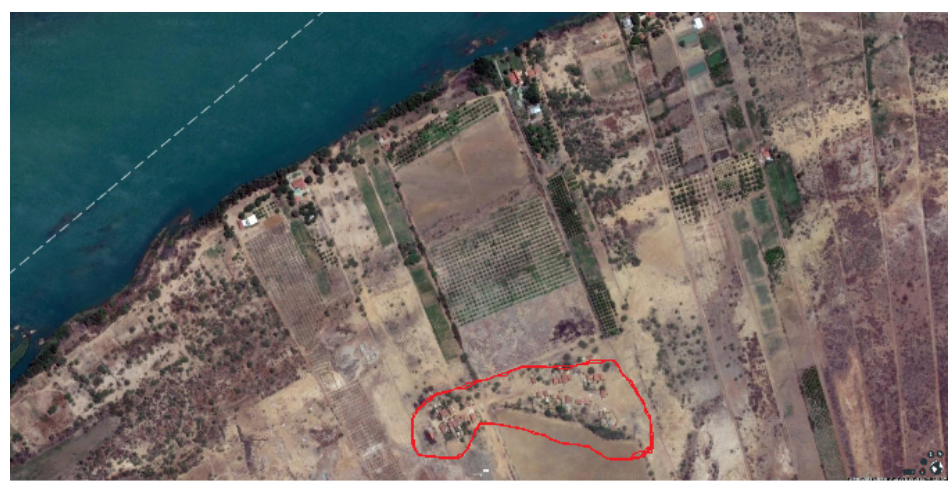

Fonte: Print do Google Earth. Acesso em: 30 de julho de 2017.

Já fora indicado por Santos (2014, p. 1) que a comunidade Alagadiço possui "uma extensão de aproximadamente três quilômetros, [e] abriga 43 famílias de origem quilombola.”, contando com “aproximadamente 120 moradores" (Santos, 2014, p. 7). Uma estimativa maior é asseverada por um dos participantes desta pesquisa, para o qual, referindo-se à ideia de família como sendo aqueles que coabitam na mesma casa: "Família já está aumentando agora. A mulherada nova tudo já têm família. [...] eu acho que já tem umas 50 a 55 famílias. Entre os velhos e os novos já têm família, sabe?” (Entrevistado $1^{7}$ ). E sobre o número de moradores, sugestiona: "Entre novos e velhos, olhe... bote umas 180 pessoas a 200 pessoas. É grande! tem esse aqui... lá tem uma vilinha, ali fora, umas casinhas ali fora... é daqui também, ali do outro lado da pista!” (Entrevistado 1).

No histórico do reestabelecimento mais recente das famílias, e de constituição da identidade nominal da comunidade, verificam-se processos de readaptação ao meio, decorrentes de fatores socioambientais locais: a mudança para uma área mais afastada do rio São Francisco em função de inundações pelas cheias de suas águas, como conta um dos entrevistados, explicando o porquê do nome Alagadiço: "Naquele tempo dos mais velhos tinha umas enchentes grandes! E aqui teve um ano... [...] alagou tudo aí. Aí eles se mudaram pra cá! E aqui é alto. Aí fizeram as casas aqui. O povo botou o nome Alagadiço." (Entrevistado 1).

Alagadiço é uma comunidade negra rural que no passado manteve a expressão de manifestações culturais características, além de manter, atualmente, práticas que foram posteriormente instituídas ou aperfeiçoadas, como a festividade católica da padroeira Santa Izabel.

Como elemento pregresso, foi apontado o "Samba de Veio", dança tradicional (e também expressão musical regionalizada) difundida nos quilombos brasileiros desde a época da escravidão e que permanece, atualmente, como um elemento folclorizado, não recebendo da sociedade em geral a mesma valorização que outras expressões artísticas e culturais. Em sua execução nessa comunidade

\footnotetext{
${ }^{7}$ Preservando-se a identidade dos participantes, utiliza-se "Entrevistado 1" e "Entrevistada 2" para identificar os participantes da entrevista gravada, e a partir do número três para os participantes do questionário.
} 
baiana (no período de Reis, por exemplo, a festa popular do Reisado), o "Samba de Veio" reunia junto a seus moradores muitos parentes, amigos e conhecidos vindos de outros lugares, como Lagoa do Salitre, Rodeadouro e Juazeiro. Hoje essa expressão permanece apenas na memória, pois se perdeu com o tempo, não sendo uma prática continuada pelas novas gerações na comunidade, como considerou a Entrevistada $2^{8}$. Ao resgatar essa memória, essa participante relembrou inclusive um pequeno trecho composto por versos de uma das cantigas que eram entoadas nas rodas de samba e que compõem o repertório da cultura popular, sendo assim cantado por ela no momento da entrevista:

Papai, mamãe, nunca peguei no alheio...

Quando a polícia chegar...

Tire meu nome do meio...

A conquista da certificação como "comunidade remanescente de quilombo", no ano de 2016, contou principalmente com o apoio da pesquisa intitulada "Perfil Fotoetnográfico das Populações Quilombolas do Submédio São Francisco: Identidades em Movimento”, coordenada pela professora e pesquisadora Márcia Guena dos Santos, do Departamento de Ciências Humanas da Universidade do Estado da Bahia (UNEB), Campus Juazeiro. Salienta a própria, em trabalho apresentado durante o "XVI Congresso de Ciências da Comunicação na Região Nordeste", no ano de 2014: utilizando a fotoetnografia como principal metodologia, "O objetivo principal da pesquisa é localizar e dar visibilidade às comunidades tradicionais de origem quilombola através da imagem e de suas histórias, para em seguida traçar relações com as construções identitárias na região, mostrando a força e a pujança dessas culturas [...].” (Santos, 2014, p. 1-2).

Através do contato possibilitado por meio da referida pesquisa, a pesquisadora pode se fazer atuante junto aos moradores de Alagadiço e apoiar um processo de mobilização dos mesmos em torno de sua certificação enquanto quilombolas e a busca atual pela titulação de suas terras junto aos órgãos responsáveis, conforme identificado em entrevista aos dois moradores. As relações possibilitadas mediante tal incursão podem, portanto, significar um incremento ao capital social na comunidade, com um potencial de mediação entre os seus interesses e as instituições políticas e representativas a nível local e estadual, além do incentivo ao sentido de mobilização ante as possibilidades de reivindicação por direitos específicos e o direcionamento de ações à população. Como aponta Lima (2001), capital social pode “[...] ser entendido como o conjunto de normas de reciprocidade, informação e confiança presentes nas redes sociais informais desenvolvidas pelos indivíduos em suas vidas cotidianas, resultando em numerosos benefícios diretos ou indiretos, sendo determinante na compreensão da ação social.” (Lima, 2001, p. 46).

\footnotetext{
${ }^{8}$ A tradição do "Samba de Veio" resiste, porém, no Rodeadouro, a outra CNRQ também certificada e que se localiza um tanto próximo a Alagadiço, igualmente às margens do rio São Francisco.
} 
Para o processo de requerimento do direito de oficialização do reconhecimento junto à FCP, a comunidade realizou uma assembleia em 23 de março de 2014, com significativa participação de comunitários, visando discutir o assunto. Nesse contexto, deu-se a redesignação da associação local, antes intitulada "Associação de Moradores, Agricultores e Criadores Rurais do Povoado de Alagadiço-Salitre e Vizinhanças", para "Associação da Comunidade dos Remanescentes Quilombolas de Alagadiço Salitre do Distrito de Junco - Juazeiro-BA”, tendo em vista que um dos critérios àqueles que pleiteiam sua certificação enquanto quilombola é a existência de organização associativa legalmente constituída na comunidade.

O caso de Alagadiço se soma a um contexto de dezenas de outras comunidades que nos últimos anos vêm ganhando maior visibilidade diante das políticas de reconhecimento, apesar dos obstáculos que se apresentam constantemente. Na história das comunidades hoje classificadas juridicamente como "remanescentes dos quilombos", o acesso a mecanismos que orientam a formalização do reconhecimento (política de reconhecimento) já representa uma maior proximidade destes grupos de ações de cunho reparativo e políticas públicas, vistas como necessárias em função da dívida histórica e da negligência sofrida desde o período escravista, além do estado de vulnerabilidade a que foram relegados e da necessidade de preservação de sua cultura. Em comunidades que já sejam certificadas, pode haver, por exemplo, o investimento em infraestrutura e serviços, como afirma Tânia Gonçalves, em sua tese de doutorado: "De acordo com as informações obtidas na pesquisa de campo, em Brasília, junto à assessoria da ministra Luiza Bairros, é licita a construção de equipamentos com destinação aos serviços públicos, em comunidades ainda não tituladas, porém certificadas." (Gonçalves, 2013, p. 55).

Em meio a essa luta pelo acesso a políticas públicas e possibilidades de modificação das condições locais, identidade e territorialidade tornam-se elementos indissociáveis, de modo que, para além do reconhecimento identitário, as comunidades se mobilizam na busca pela formalização de seu território a partir do reconhecimento da propriedade de suas terras, este que "[...] é claramente um direito fundamental de segunda geração, dizendo respeito à igualdade e à justiça social, representando [...] a conclusão do processo inacabado de abolição com a reparação da dívida histórica existente." (Figueiredo, [20--?], s/p).

Com efeito, o conflito por terras e a existência de atitudes atentatórias contra os direitos territoriais de grupos étnicos é um fato presente na realidade de muitos povos e comunidades hoje referidos como "tradicionais". E reflexos desse quadro também são constatados no histórico da comunidade Alagadiço, pois, conforme entrevistas informais oportunamente realizadas com alguns moradores, já houve tentativas de retirá-los daquela região para outra. Afirmou-se também que algumas famílias já perderam terras na região, além de outras que terminaram por vender suas áreas individuais. 
Alguns desses aspectos foram igualmente apontados nas falas produzidas por algumas participantes que responderam ao questionário (em resposta às perguntas: "O que é ser quilombola? Isso é importante para você? Por quê?"), podendo-se problematizar, a partir das mesmas, a influência do reconhecimento identitário no campo do acesso a políticas públicas relacionadas à manutenção de direitos territoriais, à medida que tais respostas permitem verificar um sentido de garantia de propriedade e permanência no território, além da influência no processo de valorização da comunidade:

Pra nós é, porque pra nós tem mais valor. Porque antes daqui ser certificado o pessoal queria tomar isso aqui e queria que a gente fosse morar lá pra cima. (Entrevistada 7).

Porque estão vindo os benefícios pra cá. Antes a gente ia perder esse terreno aqui. Pra não perder, tivemos que passar a [ter oficializado o autorreconhecimento] quilombola. (Entrevistada 12).

Ocupando, hoje, uma área diferente daquela originalmente habitada, em parte pelo seu afastamento das margens do rio São Francisco, iniciado por conta das enchentes outrora ocorridas no mesmo, como anteriormente abordado, a população de Alagadiço assistiu, ainda, à instalação de processos de ocupação da terra pelo latifúndio e o agronegócio, que foram se sobrepondo à ocupação tradicional, tolhendo também o acesso livre aos recursos hídricos fluviais. Sobre esse aspecto, como também observou Santos (2014, p. 7),

\footnotetext{
A comunidade do Alagadiço, que no passado ocupava uma grande área até as margens do rio São Francisco, a aproximadamente quatro quilômetros da comunidade, e se estendia para a direita, por mais 4 quilômetros, hoje está circunscrita a um corredor com casas dos dois lados [...]. A terra foi sendo ocupada por grandes proprietários e hoje um único dono ocupa as áreas circunvizinhas à comunidade, restringindo o espaço dos antigos moradores e bloqueando o acesso direto ao rio: de um lado o verde da propriedade irrigada e de outro a aridez do Alagadiço.
}

Esses fatores representam um dos aspectos aos quais tem sido confrontada a aplicabilidade das políticas de reconhecimento identitário e de proteção territorial enquanto medidas relativas ao cumprimento do pleno direito de permanência e posse de terras tradicionalmente ocupadas. Nesse sentido, o processo de busca pela formalização de garantias legais de valorização do aspecto identitário compreende, efetivamente, a aquisição de uma proteção territorial no contexto da comunidade Alagadiço, assim como em tantas outras comunidades quilombolas, podendo contribuir também como um estímulo ao sentido de preservação cultural em relação às tradições que podem ser esquecidas com o tempo. 


\section{CONTEXTO MAIS GERAL DO ACESSO A PROGRAMAS E SERVIÇOS NA COMUNIDADE ALAGADIÇO}

Nas últimas décadas, os povos e comunidades quilombolas têm conquistado uma maior visibilidade a partir de sua inclusão (única ou em conjunto com a de outros grupos tradicionais) em instrumentos legais normativos que determinam a implementação de ações, programas e políticas públicas para o seu atendimento. Tem-se como exemplo o Decreto $n^{\circ} 6.040 / 2007$ que, ao instituir a Política Nacional de Desenvolvimento Sustentável dos Povos e Comunidades Tradicionais (PNPCT), traz importantes direcionamentos, abordando aspectos referentes à saúde, educação, inclusão social, segurança alimentar, preservação cultural, respeito e valorização da diversidade cultural e socioambiental, preservação dos direitos culturais, da memória étnico-racial e dos saberes tradicionais, entre vários outros aspectos já previstos no PBQ, em se tratando especificamente do segmento quilombola.

No que diz respeito ao Programa Brasil Quilombola, conforme expõe documento oficial da Presidência da República, formulado no âmbito da extinta Secretaria Especial de Políticas de Promoção da Igualdade Racial (SEPPIR), o qual o caracteriza, a definição de ações no mesmo se estrutura a partir de quatro eixos: regularização fundiária, infraestrutura e serviços, desenvolvimento econômico e social, e controle e participação social (Brasil, 2009, p. 25-26). É no âmbito do PBQ que se desenvolve a Agenda Social Quilombola, cujas ações a serem desenvolvidas são compreendidas por esses quatro principais eixos: a) acesso à terra, com ações direcionadas à regularização fundiária; b) infraestrutura e qualidade de vida, com ações de promoção da saúde, saneamento básico, fortalecimento da educação quilombola e melhoria de instalações escolares, Programa Luz para Todos, apoio à recuperação ambiental de comunidades, apoio ao acesso a recursos hídricos para a produção local (construção de cisternas), entre outros; c) inclusão produtiva e desenvolvimento local, com ações que incentivem o desenvolvimento sustentável a partir das oportunidades existentes nas comunidades, a serem identificadas e apoiadas através de processos educativos voltados à geração de renda e aos aspectos econômico e social, ações de fortalecimento de instâncias produtivas ou organizativas, Programa de Aquisição de Alimentos (PAA), entre outros; e d) direitos de cidadania, com o fomento à participação e ao controle social, pelos quilombolas, no cumprimento de seus próprios direitos, além de prever ações e programas de transferência de renda e assistência social: Programa Bolsa Família (PBF), Benefício de Prestação Continuada, políticas de fomento à segurança alimentar, incluindo a ação emergencial de distribuição de cestas alimentares para comunidades e famílias em estado de vulnerabilidade nutricional, etc. (Brasil, 2009, p. 27-33).

No âmbito da agricultura familiar e das políticas públicas de apoio à sua prática, são verificadas outras políticas específicas que abordam também os quilombolas. Nesse contexto, os serviços de Assistência Técnica e Extensão Rural (ATER) (esta, que é um serviço de educação não 
formal, de natureza contínua, voltado para populações do meio rural) se inserem como medidas indispensáveis por meio das quais os beneficiários podem obter assessoria e orientações não apenas quanto à produção, mas também à gestão, beneficiamento e comercialização de atividades e serviços tanto agropecuários quanto não agropecuários, o que, segundo a Lei n ${ }^{\circ}$ 12.188/2010 (Lei de ATER), deve se dar de forma gratuita.

Outro instrumento legal que antes destes já se encarregava de orientar a inclusão dos povos quilombolas em ações de desenvolvimento rural, além de melhor situá-los no conjunto das políticas públicas de reconhecimento e defesa de direitos territoriais, o Decreto $n^{0} 4.887 / 2003$ trata da regulamentação do procedimento para a identificação, o reconhecimento, a delimitação, a demarcação e a titulação das terras habitadas por "remanescentes quilombolas". Em seu Art. 20, tal documento estipula que "para os fins de política agrícola e agrária, os remanescentes das comunidades dos quilombos receberão dos órgãos competentes tratamento preferencial, assistência técnica e linhas especiais de financiamento, destinados à realização de suas atividades produtivas e de infraestrutura." (Brasil, 2003).

Quanto ao enfoque desses aspectos na realidade observada, na comunidade Alagadiço foi unânime a indicação dos participantes quanto à inexistência de assistência técnica no âmbito da produção agropecuária familiar e também de ações de extensão rural, não se observando ações dessa natureza na comunidade até o período de início da presente pesquisa. Também na literatura não foram identificadas outras informações para além de breve referência à atuação de professores universitários em conjunto com entidades, como a extinta Empresa Baiana de Desenvolvimento Agrícola (EBDA), antiga responsável pela prestação de ações de ATER público estatal na Bahia. Nesta ação, ocorrida na década de 80 , teria se realizado "[...] um projeto de Comunicação para documentar todas as ações da comunidade. [...] nesse projeto o território e as famílias foram identificados e aconteceram oficinas de vídeo e fotografia com a finalidade de levantar os principais problemas." (Santos; Souza, 2015, p. 196). Segundo a fonte citada, tal realização teria influenciado a construção da estrada de acesso e do equipamento escolar local em Alagadiço, que será retomado mais adiante.

Por não estarem tão bem localizados no foco das atenções de instâncias locais que desenvolvem trabalhos de $\mathrm{ATER}^{9}$ e de outras ações do próprio governo, e ainda por conta da irregularidade das chuvas que é comum na região, além da dificuldade de acesso à água, é verificável um desestímulo quanto à prática da agricultura, seja para consumo próprio ou comercialização de excedente. Assim, embora se trate de uma comunidade rural e haja moradores e famílias com terra apta ao plantio, poucos produzem alimento. Menos da metade dos participantes indicaram prática da

\footnotetext{
${ }^{9}$ Com a extinção da EBDA, em 2015, hoje predomina na região, assim como em todo o estado da Bahia, o modelo de ATER público não estatal, em que as ações são executadas por Organizações Não Governamentais (ONGs) mediante processo de chamadas públicas por meio dos quais os contratos geralmente prevalecem por um período de dois anos.
} 
agricultura, a exemplo de referência feita por uma participante ao seu irmão, o qual, fazendo uso do terreno da mãe, e de equipamento para captação de água no rio, produz feijão e mandioca/macaxeira. Houve outras referências que indicaram a prática de agricultura a partir do arrendamento de terreno ou do sistema de parceria. Predominaram nas indicações as culturas macaxeira e feijão, havendo também algumas referências à abóbora, manga e coentro, dentre outros. Somente em dois casos houve referência à possibilidade de comercialização de alguma fração dos produtos.

Como se percebe, apesar da proximidade com as margens do São Francisco, um dos maiores e mais importantes rios do país, o principal problema enfrentado pela comunidade Alagadiço é a falta de acesso digno a recursos hídricos. Além de os moradores não disporem de água encanada e tratada para o consumo humano, também não acessam a água necessária às atividades agrícolas, tendo em vista os altos custos de implantação de um sistema de irrigação ou de equipamentos de captação de água que sejam mais eficientes. Isso também fica evidente no próprio depoimento do Entrevistado 1: "Nós temos roça, mas nós não plantamos não! Nós temos a roça lá na beira do rio, mas nós não temos motor pra molhar!”. Dessa forma, não se verifica tanto empenho quanto à produção de alimentos, e a sobrevivência dos animais e o próprio consumo humano dependem, em parte, da água que é transferida do rio até a comunidade através de uma bomba de captação que, conforme os Entrevistados 1 e 2, fora doada pelo governo, sendo que a água captada é usada principalmente nos períodos de seca: "Pra cozinhar, pra tudo! Porque a água é no rio. Nós não podemos pegar a água na cabeça! ${ }^{10}$ Aí essa bombinha que ele deu a nós tá servindo” (Entrevistada 2).

Quanto às atitudes de tratamento para o consumo da água que é captada do rio, conforme relato de alguns moradores, realiza-se um procedimento básico que compreende a fervura da água para o consumo pelas crianças, e a adição de água sanitária e/ou cloro para o consumo pelos adultos. Este segundo produto é distribuído para os moradores através da Unidade Básica de Saúde do povoado de Lagoa do Salitre, sendo também entregue na comunidade quando da visita mensal da equipe de saúde que se dirige ao local para realizar o acompanhamento das crianças.

Acerca da percepção e do acesso a alguns programas, a maioria dos participantes demonstrou possuir conhecimento da Declaração de Aptidão ao Pronaf (DAP) e desconhecimento acerca do que seja o próprio Pronaf ${ }^{11}$ e também o programa Garantia Safra, mas indicou no questionário que possui

\footnotetext{
${ }^{10}$ Em muitas comunidades rurais que no passado não possuíam abastecimento de água nem opções de bombeamento desta a partir de alguma fonte, as pessoas, sobretudo mulheres, jovens e até crianças, precisavam ir pegá-la em rios, fontes, lagoas, aguadas, açudes, etc., carregando-a por longas distâncias, muitas vezes a pé, e com baldes e vasilhames na cabeça, até chegar às suas residências.

${ }^{11} \mathrm{O}$ Pronaf representa a primeira política governamental direcionada unicamente à agricultura familiar. Para Costa, Rimkus e Reydon (2007, p. 6-7), trata-se de um programa criado inicialmente no ano de 1995 pelo governo de Fernando Henrique Cardoso, "como uma linha de crédito de custeio diferenciada para financiar a agricultura familiar.", a qual, depois de um ano, passaria a ser um "programa governamental" a partir do Decreto Presidencial de n 1.946/1996, sofrendo uma nova orientação e tornando-se mais abrangente. Neste sentido, "A missão fundamental do Pronaf seria combater as desigualdades (regionais, setoriais e pessoais) que marcaram as políticas públicas tradicionais voltadas para estimular a mudança da base técnica da agricultura brasileira." (Costa; Rimkus; Reydon, 2007, p. 7). Catia Grisa menciona
} 
aquele documento, o qual dá acesso a estes programas. De posse da DAP, alguns moradores estariam tendo acesso aos canais de implementação do programa Garantia Safra, conforme informado pelo Entrevistado 1, muito embora no questionário uma participante tenha ressaltado que formalizou o pedido desse auxílio através dos documentos necessários, mas não chegou a recebê-lo, desconhecendo o motivo. Em outros dois casos não se dispunham de documentos necessários ou não se atendiam a alguns critérios, além de outra situação em que não se possuía idade suficiente para participar do programa.

Além desses recursos supracitados, também se verificou na entrevista gravada que há algum tempo já houve a execução de um projeto de construção de cisternas de placas na comunidade. Estas são equipamentos de captação de água das chuvas com a função de atender ao consumo doméstico e que foram direcionadas para algumas das poucas famílias que eram beneficiárias do Programa Bolsa Família à época, estando inscritas no Cadastro Único de Programas Sociais (CadÚnico) do Governo Federal, critério comum na implementação de muitos programas e ações governamentais ${ }^{12}$. Não foi identificada nenhuma ocorrência de construção de outros modelos da referida tecnologia social, como o barreiro do tipo trincheira ou mesmo a cisterna do tipo calçadão, reservatórios de água com maior capacidade e que têm a função de apoiar o desenvolvimento de atividades produtivas agropecuárias e de geração de renda em espaços rurais.

Esses aspectos apontam para a necessidade de um repensar das oportunidades em torno do contexto da agricultura familiar quilombola, para que o apoio à sua prática constitua, de fato, a inteira efetividade de políticas aludidas ao segmento quilombola, um dos setores mais excluídos e ávidos por ações de incentivo a uma melhor inserção socioeconômica, por exemplo, o que deve estar no foco de tais ações de incentivo à agricultura familiar. Isso é o que orientam alguns instrumentos legais e o que defendem vários autores, a exemplo de Costa, Rimkus e Reydon (2007, p. 2), os quais reconhecem a marginalização a que está submetida a agricultura familiar brasileira desde os processos políticos econômicos que, no passado, beneficiaram pessoas ligadas ao "setor exportador" em detrimento das "populações rurais". Neste sentido, tais autores defendem que

O papel de qualquer política agrícola diferenciada para o fortalecimento da agricultura familiar, deve ser aumentar as "possibilidades" (de infra-estrutura, de assistência técnica, de

\footnotetext{
o Pronaf como um dos elementos por meio dos quais “[...] o ambiente institucional se altera e favorece o acesso do segmento da agricultura familiar nas arenas decisórias, acirrando o conflito e a competição por recursos (financeiros, institucionais ou políticos)." (Grisa, 2010, p. 104). Hoje o Pronaf atende diversas categorias de agricultores familiares, entre elas as compostas por integrantes de comunidades rurais quilombolas.

${ }^{12}$ O CadÚnico visa à "integração de programas sociais do Governo Federal” (Brasil, 2011, p. 20, grifos originais). Como um indicador de vulnerabilidade social, ele subsidia seleção de beneficiários para diversos programas: Programa Bolsa Família (PBF), Tarifa Social de Energia Elétrica (TSEE), Benefício de Prestação Continuada (BPC), Programa Minha Casa Minha Vida (MCMV), isenção de taxa de inscrição em concursos públicos e, no âmbito do desenvolvimento rural, o Programa de Fomento à Assistência Técnica às Atividades Produtivas Rurais, Programa Cisternas e o Programa Nacional de Reforma Agrária (MDS, 2017, p. 12), além de municiar a Previdência Social, a emissão do documento de identidade jovem (ID jovem) e da carteira do idoso.
} 
crédito, etc.) dos produtores mais pobres, para que esses possam atingir o seu "modelo ideal de funcionamento". Por exemplo, tais políticas devem considerar a capacidade dos agricultores familiares de gerar emprego e renda e as condições deles de inserção competitiva nos mercados doméstico e global. (Costa; Rimkus; Reydon, 2007, p. 2).

Num contexto mais amplo das estratégias de movimentação laboral presentes na dinâmica da comunidade Alagadiço, verifica-se que, como alternativa, alguns moradores mais jovens podem buscar uma fonte de renda a partir do trabalho em projetos de irrigação existentes na região, em trabalhos no espaço turístico da Ilha do Rodeadouro, ou mesmo em atividades do comércio ou da construção civil na cidade, entre outros. Já com relação ao questionário, a principal forma de manutenção verificada entre os participantes está relacionada ao recebimento do benefício social Bolsa Família ${ }^{13}(69 \%)$, além daqueles que recebem o benefício da aposentadoria pelo Instituto Nacional de Seguridade Social (INSS), entre outros benefícios. Ademais, o desenvolvimento de algumas atividades básicas se insere como estratégias que contribuem para a manutenção da subsistência, podendo se verificar, por exemplo, a prática da pesca para consumo próprio por alguns moradores, apesar das queixas sobre a escassez de peixes no rio São Francisco, e ainda o investimento na criação de animais por maioria das famílias indicadas no questionário. Verificou-se uma limitação quanto à influência da agricultura, associada aos fatores já discutidos.

Quanto à criação de animais, atividade comum entre muitos moradores, os ovinos representam a espécie animal mais indicada no questionário, seguida de aves e suínos. Apesar de pequenas, as criações que foram indicadas apontam para um possível potencial que pode ser estimulado no contexto da comunidade, o que não é uma realidade distante, pois, conforme informado pelo Entrevistado 1, ele próprio já teve acesso a canais de disponibilização de linhas de crédito para a aquisição de animais há alguns anos.

Pode ser verificado que na comunidade há o acesso a alguns serviços básicos, pois seus moradores dispõem do serviço de coleta de lixo, que se dá uma vez por semana, ônibus escolar para o transporte de estudantes e também dispõem de eletrificação residencial, importante recurso que foi conseguido após a participação de sua liderança em reunião deliberativa ocorrida há alguns anos na capital, Salvador. O transporte público circula pela rodovia que fica a muitos metros de distância do principal núcleo residencial, só adentrando o mesmo uma vez pela manhã e outra ao final da tarde.

Ainda na questão do acesso a serviços de saúde, para além da busca por serviços no equipamento público localizado em Lagoa do Salitre, como já colocado anteriormente, os moradores

\footnotetext{
${ }^{13}$ Sobre o PBF, conforme esclareceu o Entrevistado 1, o cadastro que viabiliza o acesso das famílias ao mesmo ainda não considerava sua especificidade quilombola, o que contrasta com as determinações propostas por alguns documentos que tratam da questão. Como informa o Guia de Cadastramento de Famílias Quilombolas no Cadastro Único para Programas Sociais, “A correta identificação dessas famílias no Cadastro Único é importante [...]. A informação qualificada permitirá a elaboração de diagnósticos das principais necessidades das famílias quilombolas, não só em um município, mas em todo o Brasil. Dessa maneira, conhecendo a quantidade, a localização e as necessidades socioeconômicas dessas famílias, é possível desenhar e implementar políticas públicas e programas sociais específicos.” (Brasil, 2011, p. 22).
} 
de Alagadiço recebiam o acompanhamento de um Agente Comunitário de Saúde que residia no mesmo povoado de Lagoa do Salitre, porém este não pode continuar atuando na comunidade: "Tinha um que era da Lagoa, que trabalhava aqui. Mas tiraram ele porque disse que ele estava com dois serviços! Aí ele escolheu o outro, que eu acho que ganhava mais um pouco. E agora não tem não!" (Entrevistado 1); "E nós queremos. Porque nós ficamos sem nada! É muito importante saúde!" (Entrevistada 2).

Nesse contexto do acesso a serviços e equipamentos de uso coletivo, pode-se verificar a capacidade de mobilização e trabalho coletivo dos moradores (como expressão do próprio capital social interno) em prol de algumas ações em âmbito local para o benefício da comunidade, como fica explícito na fala a seguir:

Aqui nós é que ajuntamos nós aqui da comunidade e fazemos nossas coisas. Esse prédio mesmo aí, ó, nós que terminamos ele, nós! [Fig. 2] Essa igreja aí, ó, nós que fizemos! Nós juntamos tudo, fomos pedindo ajuda aí uns aos outros, até que fizemos essa igreja [Figs. $3 \mathrm{e}$ 4]. E o prédio eles começaram, mas não terminaram! Aí nós terminamos! (Entrevistada 2).

Figura 2: Escola finalizada com o auxílio dos moradores da comunidade Alagadiço, desativada até o período da pesquisa.

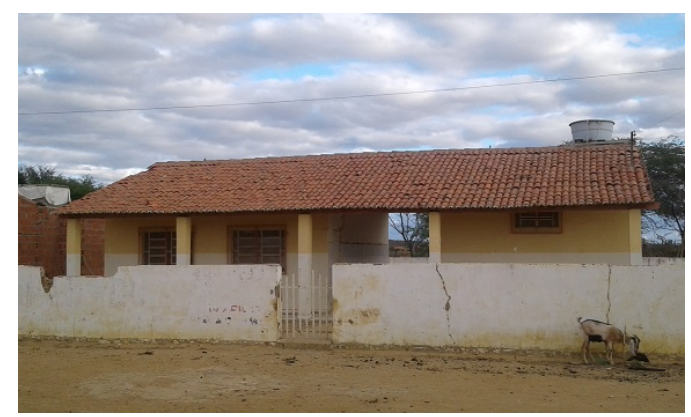

Fonte: O autor (2017).

Figuras 3 e 4: Igreja católica construída em 2010 pelos moradores da comunidade Alagadiço.

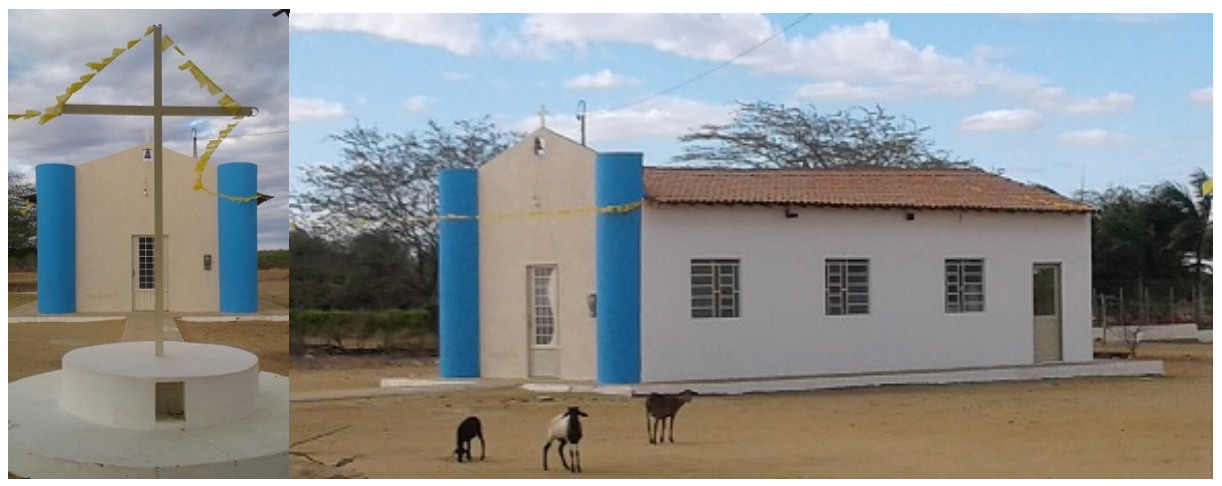

Fonte: O autor (2017). 
O "prédio" a que se referiu a Entrevistada 2 (Fig. 2), escola cuja implantação também teria sido impulsionada por ações de agentes ligados ao meio acadêmico e à EBDA, como anteriormente observado, foi uma iniciativa não concluída durante uma gestão política, e que, tendo sido retomada no período da gestão seguinte, terminou sendo finalizada com o apoio dos próprios moradores, os quais uniram esforços para ver concluso um espaço de educação escolar na comunidade. Funcionava com apenas uma turma em sistema multisseriado, o qual reunia alunos de primeira à quarta série. Até o período de realização desta pesquisa, a mesma encontrava-se desativada, possivelmente em função do baixo número de matrículas, aliado ao esquecimento dos poderes locais. Desta forma, o acesso de crianças e adolescentes quilombolas ao ensino também ocorre na localidade mais próxima, Lagoa do Salitre, convergindo com o exposto por Miranda, em sua discussão sobre o estado do direcionamento de educação formal para o segmento quilombola, para a qual "A educação escolar destinada à população remanescente de quilombos encontra-se em situação adversa, marcada pela inexistência de escolas localizadas nas comunidades ou pelo funcionamento precário das escolas existentes." (Miranda, 2012, p. 374).

Apesar de ter havido relatos de ações pontuais recentes no período de realização desta pesquisa, como a presença de equipe social na comunidade para o cadastramento de famílias no Programa Bolsa Família, os participantes não identificaram melhorias concretas na comunidade após a certificação como "remanescente quilombola", demonstrando, ao mesmo tempo, expectativas de que ocorram avanços. Paralelo ao sentimento de abandono pelos poderes locais, verifica-se um desejo por melhorias, sobretudo quanto à existência e funcionamento de um equipamento público de educação infantil e a viabilização do acesso à água encanada na comunidade. Nas palavras dos entrevistados 1 e 2: “A população quer que melhore mais. A gente luta pra um canto, luta pra outro... se for pelo lado de prefeitura... [Entrevistada 2: "Ninguém vê nada!"] aí é que não aparece nada mesmo!"' (Entrevistado 1).

De maneira geral, verifica-se uma necessidade de maior efetivação de políticas e ações capazes de desempenhar impacto positivo nas condições de vida dos moradores, nos campos da saúde e educação e, fundamentalmente, no contexto de ações de saneamento para acesso à água, entre outros. Com o devido acesso a recursos hídricos de origem fluvial, ou mesmo o gozo de maiores possibilidades de utilização de tecnologias de captação de água das chuvas, os moradores poderiam ter, inclusive, maiores estímulos para o desenvolvimento de atividades produtivas que incrementassem o autossustento e mesmo apoiassem a geração de renda. Mas isso necessitaria de maior empenho de instâncias locais, como as instituições de ATER, quanto ao acesso e acompanhamento especializado aos moradores, visando realizar com os mesmos a identificação dos potenciais locais e das melhores formas de uso de recursos. 
É preciso enfatizar, contudo, que as garantias de pleno acesso aos direitos por esse segmento estão relacionadas também aos processos de regularização fundiária e de oficialização do reconhecimento, este último ratificado pela certificação, conquista ainda recente para Alagadiço, tendo sido formalizada em 2016. Representando uma proteção do território tradicionalmente ocupado contra a investida do latifúndio, ameaça presente na trajetória da comunidade, como foi discutido, tal processo de reconhecimento pode ser fortalecido com a continuidade das etapas subsequentes (entre as quais a realização do Relatório Técnico de Identificação e Delimitação (RTID), que contempla o relatório antropológico, o levantamento dominial de imóveis, o levantamento fundiário e o levantamento agronômico, entre outras peças) e que possam levar à consolidação da obtenção do título coletivo das terras. As etapas subsequentes à certificação já estariam sendo pleiteadas junto aos órgãos responsáveis, segundo ressaltou o Entrevistado 1.

A efetivação de direitos legalmente constituídos, contudo, requer o engajamento constante da própria comunidade, a qual precisa ter bem definidos os contornos de sua própria identidade. Mas, a assunção de uma postura de engajamento na busca pelos direitos torna-se, paradoxalmente, um desafio contínuo para os sujeitos, pois além de poder esbarrar em um estado de inércia e desconhecimento para alguns, contrasta com a sua inserção num quadro de opressão, omissão, negação e racismo que passa a influenciar as representações que têm de si mesmo e de seu papel social, podendo contribuir para a neutralização do autorreconhecimento e assim vir a obstar o acesso a políticas públicas e direitos que lhes são reservados, como discutido por Santos e Doula (2008), por exemplo.

Através do próprio questionário utilizado nesta pesquisa, constatou-se resposta com este referido sentido de inércia sobre a própria identidade atribuída ("Eu ainda nem me fiz essa pergunta. Não parei pra analisar não.” - Entrevistada 12), e respostas nas quais há afirmação de um desconhecimento sobre o que é ser quilombola: "Entendo pouco sobre ser quilombola." (Entrevistada 6); “Eu não entendo não. Não entendo de jeito nenhum.” (Entrevistada 4); "Não entendo essas coisa não." (Entrevistada 10); "Sei não." (Entrevistados 15). Cabe observar, quanto a isso, que a conceituação da identidade étnica nesse contexto, de fato, não é algo tão simples, pois, além de tudo, se insere num complexo contexto histórico em que existem disputas em torno da noção de quilombo e uma constante demanda por processos de ressignificação, o que ocorre mesmo no universo acadêmico e se reverbera no campo jurídico-normativo. Ademais, na dinâmica cotidiana das comunidades, muitas vezes as lideranças, por circularem em outras arenas, por atuarem junto a diversas entidades, têm maior acesso a diversas reflexões sobre o termo e o processo de demanda por reconhecimento, o que nem sempre acontece com aqueles/as que circulam apenas nos espaços mais próximos. 
Um dos participantes, ao proceder à consideração de um pertencimento étnico-racial para explicar o que é ser quilombola, reconheceu, em paralelo, o referido aspecto do racismo que persiste na sociedade: "As famílias negras de antigamente. Racismo terrível! Aqui acolá ainda tem esse racismo." (Entrevistado 3).

Num sentido contrário aos eventos de inércia e desconhecimento que foram apontados, assim como essa última fala acima (produzida pelo Entrevistado 3), há outras respostas que conseguem expressar uma maior apropriação do aspecto identitário, como fala que valoriza o resgate identitário e exalta o pertencimento étnico-racial ao explicar o que é ser quilombola: "Resgatar a minha origem. Orgulho da minha pele, da minha cor, que é negra." (Entrevistada 5); fala que identifica uma estima relacionada ao pertencimento étnico-racial: "Modo de respeito pra nós que somos pretos." (Entrevistada 8); e fala que afirma a identidade quilombola como algo eminente e como herança cultural: “É coisa muito importante, a pessoa ser quilombola, né. Tradição.” (Entrevistada 11).

Aponta-se, assim, a complexidade na qual se insere a autopercepção da identidade quilombola e das ancestralidades, podendo as mesmas serem mais bem apropriadas por alguns em detrimento de uma incipiente apropriação por outros, resultado da diversidade de formas de conhecimento, interação e significação da própria história, contrastadas no complexo âmbito das relações raciais no Brasil, na própria dinâmica das comunidades e vivências dos sujeitos, como já mencionado.

Esses grupos viveram situações as mais variadas, de modo que a identidade não é estática, mas resultado de vários processos pelos quais tais populações passam, e a reivindicação do reconhecimento é um desses processos. Assim, na trajetória quilombola, em contexto brasileiro, mesmo que tenham expressões carregadas de forte herança cultural e ancestralidade africana, muitas pessoas e grupos, sob influência da imersão num emaranhado de relações e no histórico processo de (res)significações, como exposto, ainda margeiam no processo de assimilação de determinados significados dos termos "quilombo" e "quilombola", classificações que, por outro lado, se inserem como categorias postas pelo Estado para identificar essas comunidades, e que, como tal, também precisam ser problematizadas dentro desse contexto, pois, para algumas dessas populações, são novas e cheias de implicações.

De todo modo, é nesse polo de apropriação, quando o mesmo pende para um distanciamento da identidade, contribuindo para sua negação, que podem se localizar também os fundamentos de cerceamento de prerrogativas fundamentais desse segmento étnico, de modo que "A negação da identidade quilombola retarda a efetiva existência destes atores, pois precisam emergir como comunidade perante os grupos sociais localizados em seu entorno e assumir [...] consciência identitária para assegurarem quaisquer direitos que oficialmente detêm.” (Santos; Doula, 2008, p. 76).

Assim, diante desse contexto marcado por vários impasses, sem a necessária disposição para a (re)apropriação do conhecimento de sua história, dificilmente se poderá perceber sob quais bases 
se fundamenta a necessidade de ações orientadas ao atendimento daqueles que constituem o segmento quilombola. Tampouco se pode estabelecer uma legítima reivindicação perante a incumbência do Estado, de suas instituições formuladoras de políticas públicas (incluindo o governo, que está entre as instituições mais eminentes do Estado, sendo "produtor, por excelência, de políticas públicas" (Souza, 2006, p. 22)) e das redes e agentes responsáveis pelo processo de implementação.

\section{CONSIDERAÇÕES FINAIS}

Abordou-se aqui o acesso a políticas públicas e o contexto de mobilização na recémcertificada CNRQ Alagadiço, no município de Juazeiro-BA, antes distante de maiores garantias legais de acesso a direitos fundamentais, agora mais à frente no campo do reconhecimento de sua especificidade ante as atenções do Estado.

Em contraposição a uma gama de políticas públicas voltadas para o atendimento de grupos étnicos de identidade coletiva autodefinida, entendidos como ávidos por ações interventoras e de reparação à situação de vulnerabilidade histórica, o que se verifica na realidade abordada é uma incipiente atenção do poder público quanto à viabilização desses aparelhos em prol do apoio à realidade das famílias quilombolas, a começar pela promoção do acesso a serviços básicos, como os de educação, saúde e principalmente o abastecimento de água potável.

Como verificado, apesar do acesso a uns poucos direcionamentos do governo e do poder público local desde antes de a comunidade pleitear o reconhecimento oficial da identidade quilombola, as ações identificadas até o período analisado tendem a uma atenção generalista, muitas vezes assentada somente num aspecto rural, sem abordar o contexto da especificidade étnica em meio ao conjunto dos beneficiários, o que também se deve ao fato de a oficialização desse reconhecimento ser uma prerrogativa recém-adquirida. Como exemplo, foram aqui apontados alguns eventos de acesso a crédito e programas básicos de apoio à agricultura familiar, o acesso a uns poucos recursos para melhor convivência com a seca, e o acesso a benefícios como Programa Bolsa Família.

Nesse sentido, permanece ainda como ponto fundamental o pleito pela efetivação da política pública de reconhecimento identitário e direitos territoriais, a qual se insere como articuladora do acesso a demais componentes inseridos no mesmo rol de direitos, entre os quais: a possibilidade de gozo de serviços básicos indispensáveis e que se mostram mais exequíveis face à realidade da comunidade, como aqueles circunscritos ao campo da educação e do acesso a recursos hídricos, elementos que foram mais enfatizados pelos quilombolas entrevistados.

Alagadiço é uma CNRQ que, como muitas outras, se insere numa marcante questão histórica ainda não resolvida, expressão de uma árdua trajetória da população negra e do segmento quilombola em contexto brasileiro, apontados como setores de vulnerabilidades no âmbito das relações 
sociorraciais. Em meio a esse paradoxo quadro observado, em que o pleno acesso a serviços indispensáveis ainda se configura como um grande desafio, verifica-se, em contrapartida, que o processo de afirmação identitária e de mobilização, que possibilitou à comunidade alcançar o reconhecimento oficial da especificidade étnica, trazem novas perspectivas de reposicionamento no contexto do acesso a políticas públicas, já possibilitando, efetivamente, algumas condições à garantia de direitos territoriais, podendo contribuir também como estímulo aos esforços de preservação da memória negroquilombola.

É notável que a efetividade da aplicação de direitos a partir da implementação de ações também requer um maior e contínuo engajamento da própria comunidade, cuja participação no controle social das políticas públicas, inclusive, é uma prerrogativa presente nos instrumentos normativos que regem a aplicação das ações. Cabe aos sujeitos, sobretudo aqueles mais alheios a esse processo, despertarem para as possibilidades de maior participação na busca pela transformação da própria realidade, para o que podem contar fundamentalmente com o potencial dos próprios instrumentos que já dispõe a comunidade, como as possibilidades organizativas através de sua formação associativa (espaço de agenciamento do capital social local, quando há envolvimento efetivo), e espaços de discussão e participação junto a instituições locais e estaduais, e junto aos movimentos sociais, como já se observa o engajamento de sua liderança em meios de participação no sentido de representação da comunidade e dos seus interesses coletivos.

\section{REFERÊNCIAS}

ALMEIDA, A. W. B. de. Os Quilombos e as Novas Etnias. In: O’DWYER, E. C. (Org.). Quilombos: identidade étnica e territorialidade. Rio de Janeiro: FGV, 2002, 296p.

ALMEIDA, A. W. B. de. Quilombos: Repertório Bibliográfico de uma Questão Redefinida (19951997). Revista Brasileira de Informação Bibliográfica em Ciências Sociais - BIB, Rio de Janeiro, $\mathrm{n}$. 45, p. 51-70, 1 sem./1998.

BRASIL. Micro dados do Censo Demográfico 2010. Instituto Brasileiro de Geografia e Estatística, 2010.

BRASIL. Senado Federal. Constituição da República Federativa do Brasil. Brasília, DF, 1988.

BRASIL. Presidência da República. Decreto $n^{\circ} 4.887$, de 20 de novembro de 2003. Regulamenta o procedimento para identificação, reconhecimento, delimitação, demarcação e titulação das terras ocupadas por remanescentes das comunidades dos quilombos. Disponível em: http://www.planalto.gov.br/ccivil_03/decreto/2003/d4887.htm. Acesso em: 01 ago. 2017.

BRASIL. Presidência da República. Decreto $n^{\circ}$ 6.040, de 7 de fevereiro de 2007. Institui a Política Nacional de Desenvolvimento Sustentável dos Povos e Comunidades Tradicionais. Disponível em:< http://www.planalto.gov.br/ccivil_03/_ato2007-2010/2007/decreto/d6040.htm>. Acesso em 01 ago. 2017.

BRASIL. Presidência da República. Lei n. 12.188, de 11 de janeiro de 2010. Institui a Política Nacional de Assistência Técnica e Extensão Rural para a Agricultura Familiar e Reforma Agrária PNATER e o Programa Nacional de Assistência Técnica e Extensão Rural na Agricultura Familiar e 
na Reforma Agrária - PRONATER, altera a Lei no 8.666, de 21 de junho de 1993, e dá outras providências. [2010a]. Disponível em: http://www.planalto.gov.br/ccivil_03/_Ato20072010/2010/Lei/L12188.htm. Acesso em: 30 jul. 2017.

BRASIL. Ministério do Desenvolvimento Social. Guia de Cadastramento de Famílias Quilombolas. 3. ed., 135 p. Brasília-DF, 2011. Disponível em:< http://www.mds.gov.br/webarquivos/arquivo/cadastro unico/ Guia de Cadastramento de Familia s_Quilombolas.pdf $>$. Acesso em: 07 ago. 2017.

BRASIL. Presidência da República. Portaria $n^{\circ} 103$, de 16 de maio de 2016. Diário Oficial da República Federativa do Brasil. Brasília, DF, 20 de maio de 2016. Disponível em:< http://www.palmares.gov.br/wp-content/uploads/2016/05/MAIO-2016-

CERTIFICA\%C3\%87\%C3\%83O-1.pdf>. Acesso em 29 jul. 2017.

BRASIL. Presidência da República. Secretaria Especial de Políticas de Promoção da Igualdade Racial. Guia de Políticas Públicas para Comunidades Quilombolas: Programa Brasil Quilombola. Brasília, 2013. Disponível em: http://www.seppir.gov.br/portal-antigo/arquivos-pdf/guia-pbq. Acesso em: 17 jul. 2017.

BRASIL. Presidência da República. Secretaria Especial de Políticas de Promoção da Igualdade Racial. Programa Brasil Quilombola: Comunidades Quilombolas Brasileiras: Regularização Fundiária e Políticas Públicas. Brasília, 2009. Disponível em: http:/www.seppir.gov.br/portalantigo/.arquivos/pbq.pdf/view. Acesso em: 17 jul. 2017.

CARVAlHO, J. M. de. Primeiros passos (1822-1930). In: CARVALHO, J. M. de. Cidadania no Brasil. O longo Caminho. 3. ed. Rio de Janeiro: Civilização Brasileira, 2002.

COSTA, J. P.; RIMKUS, L. M.; REYDON, B. P. Agricultura familiar, tentativas e estratégias para assegurar um mercado e uma renda. 2007. Disponível em: http://www.sober.org.br/palestra/9/846.pdf. Acesso em: 02 ago. 2017.

FIGUEIREDO, L. M. Remanescentes de quilombos, índios, meio ambiente e segurança nacional: ponderação de interesses constitucionais. [20--?]. Disponível em: $<$ http://www.mpf.mp.br/atuacaotematica/ccr6/documentos-e-publicacoes/artigos/docs/artigos/docs_artigos/remanescentes-dequilombos-indios-meio-ambiente-e-seguranca-nacional-ponderacao-de-interesses-constitucionaisleandro-mitidieri>. Acesso em: 30 jul. 2017.

GEOGRAFIA DOS ASSENTAMENTOS NA ÁREA RURAL (GeografAR), Universidade Federal da Bahia. Comunidades Negras Rurais Quilombolas Identificadas na Bahia, 2010. [2011]. Disponível em: $<$ https://geografar.ufba.br/sites/geografar.ufba.br/files/geografar_tabela_2010_cnrquilombolas.pdf $>$. Acesso em: 29 de Jul. de 2017.

GONÇALVES, T. A. V. Tornar-se quilombola: políticas de reconhecimento e educação na comunidade negra rural de Santana (Quatis, RJ). Tese (Doutorado em Educação) - Pontifícia Universidade Católica do Rio de Janeiro, Rio de Janeiro, Março/2013.

GRISA, C. Diferentes olhares na análise de políticas públicas: considerações sobre o papel do Estado, das instituições, das ideias e dos atores sociais. Sociedade e Desenvolvimento Rural, v.4, n., jun./2010.

HOWLETT, M; RAMESH, M; PERL, A. “Introdução: por que estudar Política pública?” In: HOWletT, M.; RAMESH, M; PERL, A. Política Pública: seus ciclos e subsistemas: uma abordagem integral. (Trad.: HEIDEMANN, F. G.), tradução da 3. ed. Rio de Janeiro: Elsevier, 2013 [2009], p.03-19.

LIMA, J. C. A teoria do capital social na análise de políticas públicas. Política \& Trabalho, João Pessoa-PB, ano17, n. 17, p. 46-63, setembro/2001.

MIRANDA, S. A. de. Educação escolar quilombola em Minas Gerais: entre ausências e emergências. Revista Brasileira de Educação, v. 17, n. 50, p. 369-498, mai./ago. 2012. 
MINISTÉRIO DO DESENVOLVIMENTO SOCIAL (MDS). O que é o Cadastro Único para Programas Sociais do Governo Federal e qual a sua importância? In:

Manual de Gestão do Cadastro Único para Programas Sociais do Governo Federal. 3. ed. 2017, p. 7-16.

PEIXOTO, M. Extensão rural no Brasil: uma abordagem histórica da legislação. Textos para discussão 48. Consultoria Legislativa do Senado Federal - Coordenação de Estudos. Brasília, 2008. Disponível $\quad \mathrm{em}:<$ https://www12.senado.leg.br/publicacoes/estudos-legislativos/tipos-deestudos/textos-para-discussao/td-48-extensao-rural-no-brasil-uma-abordagem-historica-dalegislacao $>$. Acesso em: 05 fev. 2018.

SANTOS, A.; DOULA, S. M. Políticas Públicas e Quilombolas: questões para debate e desafios à Prática Extensionista. Revista Extensão Rural, DEAER/PGExR - CCR - UFSM, Ano XV, n. 16, jul./dez., 2008.

SANTOS, M. G. dos. Perfil da comunidade quilombola do Alagadiço: entre textos e imagens (Juazeiro-Ba). In: XVI CONGRESSO DE CIÊNCIAS DA COMUNICAÇÃO NA REGIÃO NORDESTE, João Pessoa-PB, 2014, 15 p. $\quad$ Disponível em: $<$ http://portalintercom.org.br/anais/nordeste2014/resumos/R42-1751-1.pdf $>$. Acesso em: 17 jul., 2017.

SANTOS, M. G. dos; SOUZA, U. V. de. Revisando memórias e reinventando identidades nos álbuns de famílias de comunidades quilombolas. Revista Passagens, Ceará, v. 6, n. 2, p. 184-204, 2015.

SOUSA, J. R. M. de. Quilombos (palenques), terra de preto: identidades em construção. Revista Brasileira do Caribe, São Luís, v. 11, n. 22, p. 33-57, jan./jun., 2011.

SOUZA, C. Políticas Públicas: uma revisão da literatura. Sociologias, Porto Alegre, ano 8, n. 16, p. 20-45, jul./dez., 2006. 